See Article page 211.

\section{Commentary: Measure twice, cut once: Does a 'STICH' in time truly save nine?}

\author{
Gabor Bagameri, MD, and John M. Stulak, MD
}

In the current manuscript, Adhyapak and colleagues ${ }^{1}$ report the findings of their pilot study, which aimed to define the patient populations with ischemic cardiomyopathy that may benefit from surgical ventricular restoration (SVR). The basic premise and hypothesis of their study is that patients with preserved relative wall thickness (RWT) might be better candidates for left ventricular surgical remodeling (LVSR). This assumption does intuitively make sense, but it is important to note that none of the patients in the current series actually underwent SVR. After prospectively following patients with and without preserved RWT on maximum guideline-directed medical therapy using serial echocardiography and baseline B-type natriuretic peptide (BNP), the authors extrapolated data from SVR registries. Even though the lack of patients with SVR is the study major limitation, I would like to commend the authors for the efforts to identify a simple method using RWT and baseline BNP as a surrogate marker to identify patients who could benefit from LVSR.

The Surgical Treatment for Ischemic Heart Failure (STITCH) randomized clinical trial (RCT) evaluated the benefit of adding LVSR to coronary artery bypass surgery (CABG), and it showed no survival or functional benefit. ${ }^{2}$ It has been extensively criticized for its flaws and limitations, not representing the "real-world" experience, and it sharply contradicts the favorable outcomes of SVR in many retrospective studies and registries. Since RCTs are recognized as the gold standard method in the evaluation of the treatment effect, and they are at the top of the

\footnotetext{
From the Department of Cardiovascular Surgery, Mayo Clinic College of Medicine and Sciences, Rochester, Minn.

Disclosures: The authors reported no conflicts of interest.

The Journal policy requires editors and reviewers to disclose conflicts of interest and to decline handling or reviewing manuscripts for which they may have a conflict of interest. The editors and reviewers of this article have no conflicts of interest.

Received for publication June 10, 2021; revisions received June 10, 2021; accepted

for publication June 18, 2021; available ahead of print July 7, 2021.

Address for reprints: John M. Stulak, MD, 200 First St SW, Rochester, MN 55905 (E-mail: Stulak.john@mayo.edu).

JTCVS Open 2021;7:221-2

2666-2736

Copyright (C) 2021 The Authors. Published by Elsevier Inc. on behalf of The American Association for Thoracic Surgery. This is an open access article under the CC BY-NCND license (http://creativecommons.org/licenses/by-nc-nd/4.0/).

https://doi.org/10.1016/j.xjon.2021.06.013
}

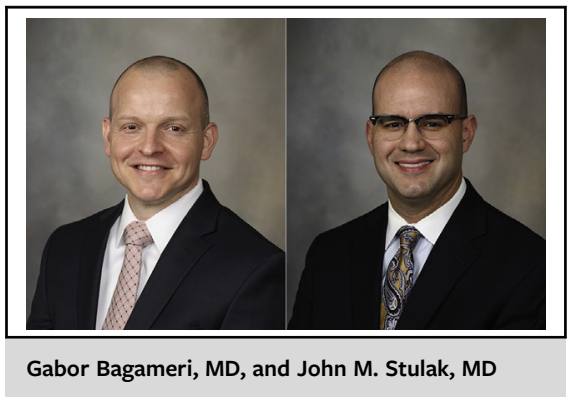

\begin{abstract}
CENTRAL MESSAGE
Randomized clinical trials can

have significant shortcomings,

especially when it comes to

operative procedures. We need

to remember to individualize

rather than generalize therapy.
\end{abstract}

"evidence pyramid," we cannot just simply dismiss results of the STITCH trial. However, RCTs do have significant shortcomings, especially when it comes to operative procedures. While they compensate for treatment selection bias, they introduce entry selection bias. Even though the STITCH trial concluded that SVR + CABG was no better than $C A B G$ in patients with congestive dilated cardiomyopathy, there is enough evidence that SVR works in wellselected patients with the correct surgical technique.

Calafiore and colleagues ${ }^{3}$ reported excellent outcomes of their SVR experience that started after the STITCH trial was first reported with an $81 \%$ 5-year survival in patients before the onset of severe mitral regurgitation or diastolic dysfunction. In their study, SVR lowered the left ventricular volume index by $>30 \%$, they and achieved excellent survival while operating on the right patients. The success of the SVR lay in the identification of discrete area of akinesis/dyskinesis with enough contractile myocardium left behind. Left ventricular diastolic dysfunction or restrictive filling pattern is a poor prognostic indicator in the setting of ischemic cardiomyopathy and SVR, and it is a relative contraindication for SVR. However, Fantini and colleagues ${ }^{4}$ showed that restrictive filling pattern can be successfully reversed if the RWT was preserved in the remaining myocardium. The response remained stable over follow-up, and it was accompanied with significant improvement within the New York Heart Association class.

The authors deduce from their limited pilot study that SVR is a viable option in the well-selected patient with 
ischemic cardiomyopathy. Two easily measured parameter (RWT and BNP) can serve as surrogate parameters to identify the right patients who will benefit from SVR. As such, while the results of a gold-standard clinical trial may not have demonstrated benefit, we need to individualize rather than generalize this therapy and, in doing so, the true benefit will be maximized. The authors have helped the readership more closely identify those patients in whom outcomes may be improved.

\section{References}

1. Adhyapak SM, Parachuri VR, Thomas T, Varghese K. Left ventricular function and survival in ischemic cardiomyopathy: implications for surgical ventricular restoration. J Thorac Cardiovasc Surg Open. 2021;7:211-8.

2. Hassanabad AF, MacQueen KT, Ali I. Surgical treatment for ischemic heart failure (STICH) trial: a review of outcomes. J Card Surg. 2019;34:1075-82.

3. Calafiore AM, Iacò AL, Amata D, Castello C, Varone E, Falconieri F, et al. Left ventricular surgical restoration for anteroseptal scars: volume versus shape. J Thorac Cardiovasc Surg. 2010;139:1123-30.

4. Fantini F, Toso A, Menicanti L, Moroni F, Castelvecchio S. Restrictive filling pattern in ischemic cardiomyopathy: insights after surgical ventricular restoration. J Thorac Cardiovasc Surg. 2019;161:651-60. 